\section{Bleeding angiodysplasia of the jejunum without a visible vessel}

A 45-year-old man with melena and dyspnea on effort that had persisted for a week was admitted to our hospital. He had serious complications such as diabetic nephropathy and myocardial infarction, and was given an antiplatelet agent. His blood hemoglobin level dropped to $4.2 \mathrm{~g} / \mathrm{dl}$, but the vital signs were stable. He underwent esophagogastroduodenoscopy and colonoscopy on day 1 of hospitalization, but the bleeding source was not identified. He received blood transfusions for 5 days.

On day 4 in hospital, double-balloon endoscopy (DBE) with an anterograde approach was done ( $\bullet$ Video 1 ).

Fresh blood was seen in the upper jejunum ( $\bullet$ Fig. $1 \mathbf{a}$ ), and when the intestine was filled with water, active bleeding was found without a visible vessel (॰ Fig. 1 b).

After normal saline injection, cauterization was done using argon plasma coagulation (APC) and hemoclipping ( $\bullet$ Fig. 2). The bleeding was stopped successfully with no sign of recurrence.

Angiodysplasia of the small intestine has been acknowledged as a major source of obscure gastrointestinal bleeding [1]. The vascular lesions of the small intestine have a variety of endoscopic appearances, and some types of vascular disease are difficult to find because of their subtle appearance. Yano et al. classified vascular lesions of the small intestine into six categories [2]. In the present case the lesion was classified as type 1 a (punctulate erythema $[<1 \mathrm{~mm}]$, with or without oozing) in the Yano-Yamamoto classification [2]. This type of angiodysplasia is considered difficult to find, if spontaneous transit hemostasis is completed. Therefore, early DBE was essential for accurate diagnosis and endoscopic hemostasis in the present case.

Endoscopy_UCTN_Code_CCL_1AC_2AB out a visible vessel.

Fig. 2 Double-balloon endoscopy (DBE) coagulation (APC) and hemoclipping.

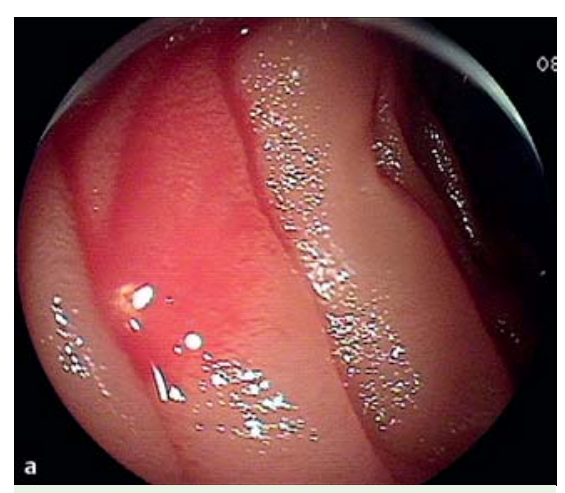

\section{K. Hotta, K. Yoshida}

Department of Gastroenterology, Saku

Central Hospital, Nagano, Japan

\section{References}

1 Ell C, May A, Nachbar L et al. Push-and-pull enteroscopy in the small bowel using the double-balloon technique: result of a prospective European multicenter study. Endoscopy 2005; 37: 613-616

2 Yano T, Yamamoto H, Sunada $K$ et al. Endoscopic classification of vascular lesions of the small intestine (with videos). Gastrointest Endosc 2008; 67: 169 - 172

\section{Bibliography}

DOI $10.1055 / \mathrm{s}-0029-1214433$

Endoscopy 2009; 41: E253

(c) Georg Thieme Verlag KG Stuttgart · New York . ISSN 0013-726X

Corresponding author

\section{K. Hotta, MD}

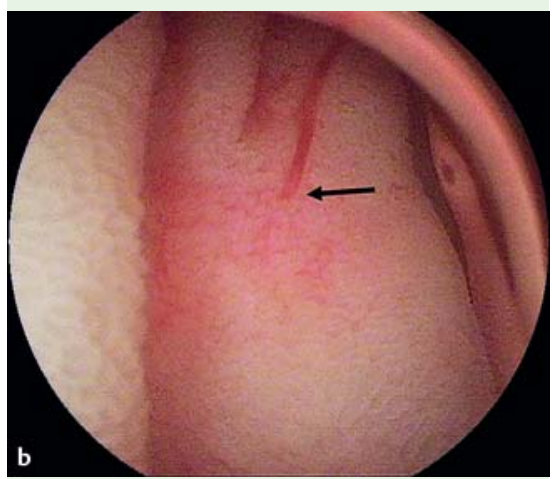

197 Usuda, Saku

Nagano, 384-0301

Japan

Fax: +81-267-823025

kinichi1@janis.or.jp

Fig. 1 a Double-balloon endoscopy (DBE) o the upper jejunum showed fresh blood on the mucosal surface. $\mathbf{b}$ DBE in the water-filled intestine showed a bleeding spot (arrow) with-

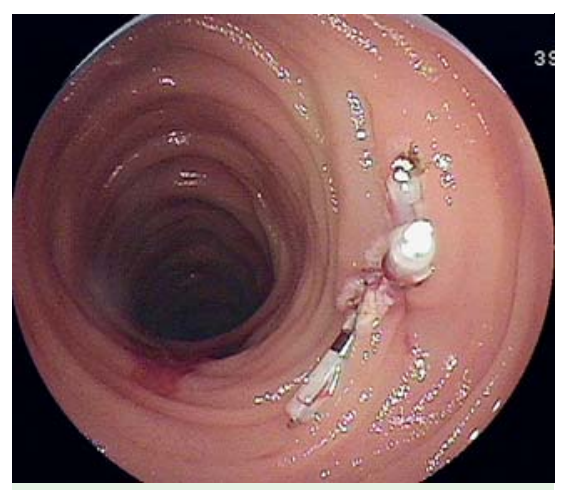
showed hemostatic state after argon plasma

\section{Video 1}

Double-balloon endoscopy (DBE): diagnosis and hemostatic treatments of bleeding angiodysplasia of the jejunum. 